\title{
OSL Dating of Sea Floor Sediments at the Okinawa Trough
}

\author{
Vaidehi Varma, Shin Toyoda, Yusuke Isono, Ai Uchida, \\ Debabrata Banerjee, Ashok Kumar Singhvi, and Jun-ichiro Ishibashi
}

\begin{abstract}
In estimating the ages of sea floor hydrothermal deposits, the age of the sediments overlying it would give the youngest limit if the sedimentation age is correct. The OSL (optically stimulated luminescence) method was applied to two sediment cores taken by an acrylic corer from the seafloor in the Okinawa Trough. The ages, obtained by the polymineral fine grain method, did not correlate with the stratigraphic sequence within the core, implying either insufficient bleaching of the sediments at the time of the deposition or mixing of sediments of different ages. The polymineral fine grain OSL dating method did not work to date the present sediment samples at the sea floor in the Okinawa Trough.
\end{abstract}

Keywords

OSL dating $\bullet$ Polymineral fine grain $\bullet$ Sea floor sediment

\subsection{Introduction}

The ages of hydrothermal deposits are important to investigate the evolution of the hydrothermal systems. Various dating techniques have been employed, such as U-Th method on sulfide minerals (Takamasa et al. 2013), ESR method on barite (Takamasa et al. 2013; Fujiwara et al. (2014), Chap. 34), and ${ }^{226} \mathrm{Ra}^{2}{ }^{210} \mathrm{~Pb},{ }^{228} \mathrm{Ra}^{228} \mathrm{Th}$ method on barite (Noguchi et al. 2004; Uchida et al. (2014), Chap. 41) to provide clues to discuss the evolution of the hydrothermal activities. In the present data report, optically stimulated

V. Varma $(\bowtie) \cdot$

D. Banerjee - A.K. Singhvi

Physical Research Laboratory, Ahmedabad, India

e-mail: vaidehi_varma@yahoo.in

S. Toyoda $\bullet$ Y. Isono $\bullet$ A. Uchida

Okayama University of Science, Okayama, Japan

J.-i. Ishibashi

Kyushu University, Fukuoka, Japan luminescence (OSL) dating technique was applied to the sediments from the Okinawa Trough.

OSL dating techniques have been widely applied for dating the sedimentary deposits and gave the age of last sun exposure or the age of burial, using naturally occurring minerals, for instance, like feldspar or quartz, present in the sediments. At the time of transportation of sediments, exposure to the sun would completely bleach and reset the OSL signal in them. After their deposition, the natural radioactivity of uranium (U), thorium (Th) and potassium (K) would deposit dose cumulatively over time which would be measured in laboratory as the equivalent dose $\left(D_{e}\right)$ in Gray (Gy). The given radiation dose per year is measured as a dose rate in $\mathrm{Gy} / \mathrm{year}$. The ratio of $\mathrm{D}_{\mathrm{e}}$ to dose rate gives the age in year of the sediment (Aitken 1998).

The sections of samples collected at Okinawa Trough showed the signature of sulfide deposits. At the sea floor, as time passes, previously formed sulfide deposits by hydrothermal activities, are covered with sediments. If ages of the sediments are obtained by OSL, the ages would give the youngest age limit of the deposits beneath them. This is a pilot study to apply the OSL dating technique to date the sea floor sediments in the aspect of dating of deposits formed by hydrothermal activities. 


\subsection{Samples and Sites of Collection}

Two sediment cores were taken by an acrylic (MBARI type) push corer and examined in the present study. One core, HPD1330M1, was taken at Irabu Knoll, the Okinawa Trough $\left(25^{\circ} 14.378^{\prime} \mathrm{N}, 124^{\circ} 52.863^{\prime} \mathrm{E}\right.$, depth $\left.1,978 \mathrm{~m}\right)$, during the NT11-20 cruise operated by JAMSTEC in 2011 while the other, HPD1357MB, was at Iheya North Knoll $\left(27^{\circ} 47.301^{\prime} \mathrm{N}, 126^{\circ} 54.538^{\prime} \mathrm{E}\right.$, depth $\left.1,109 \mathrm{~m}\right)$ during NT1206 cruise in 2012. A transparent acrylic tube, $10 \mathrm{~cm}$ in diameter and $30 \mathrm{~cm}$ in length, was inserted in the sediment by a manipulator of ROV Hyper Dolphin, and the core was retrieved to the submarine vehicle. The core samples were wrapped by $\mathrm{Al}$ foils and kept frozen as soon as possible after sample retrieving onboard. The frozen cores were cut in a dark room to separate three sections, top, middle, and bottom (Table 48.1). The part of the surface facing to the tube of each section was trimmed out and used for the measurements of water content and dose rate. The rest inside part of the tube was used for OSL measurements. The water contents were obtained by the weights of the sections before and after drying. After measuring the water contents, the dried section samples were used for gamma ray spectrometry to obtain $\mathrm{U}, \mathrm{Th}$, and $\mathrm{K}$ concentrations.

\subsection{Sample Preparation and Experiments}

The sediment samples used to estimate the equivalent doses $\left(D_{e}\right)$ using OSL technique consisted dominantly finer fraction $(<11 \mu \mathrm{m})$. Thus, the $\mathrm{D}_{\mathrm{e}}$ 's were measured using the polymineral fine grain $(4-11 \mu \mathrm{m})$ technique (Zimmerman 1971). The preparation of polymineral fine grain sample discs was the following; chemical treatments with $1 \mathrm{~N} \mathrm{HCl}$ to remove carbonate and with $30 \% \mathrm{H}_{2} \mathrm{O}_{2}$ to remove organic matter, deflocculation using $0.01 \mathrm{~N}$ Sodium Oxalate, and Stokes settling in absolute $(80 \%)$ alcohol to obtain desired grain fraction $(4-11 \mu \mathrm{m})$. The separated grains were then re-suspended in alcohol. Equal volume of this solution was pipetted into sample tubes $(10 \mathrm{~mm}$ in diameter) with an aluminum disc at the base. The alcohol was evaporated off at $45^{\circ} \mathrm{C}$ to obtain a thin $(\leq 20 \mu \mathrm{m}$ thickness) layer of sample on the discs. A set of 24 discs were prepared for each sample.

An automated Ris $\varnothing$ TL-OSL reader (TL/OSL-DA-20; Bøtter-Jensen et al. 2010) was used for $D_{e}$ measurements. Fine grain polymineral samples were stimulated using IR diodes $(870 \pm 40 \mathrm{~nm})$ and detection was made in the violetblue emission window $(395 \pm 50 \mathrm{~nm})$ using a filter combination of Schott BG-39 and Corning 7-59. The bulk signal was dominated by the signal from feldspar. Since feldspar can be stimulated by IR (Hütt et al. 1988), IRSL SAR protocol (Murray and Wintle 2000; Blair et al. 2005) was used. The protocol is shown in Table 48.2. This same protocol was used for all the 24 discs of each sample. The final $D_{e}$ value is the average of these 24 values.

Dose rate was calculated using the concentration of $\mathrm{U}$, $\mathrm{Th}$, and $\mathrm{K}$ and the water content in sediments. Radionuclide concentrations were measured using a low background gamma ray spectrometry. Water content was estimated as per Aitken 1985. Cosmic ray dose was not considered as the samples were at sea floor and would be completely attenuated.
Table 48.2 IRSL SAR protocol used for ED measurements

\begin{tabular}{lll}
\hline Step & Operation & Comment \\
\hline 1 & $\beta$ dose & For natural, dose $=0$ \\
\hline 2 & Preheat $260{ }^{\circ} \mathrm{C}, 60 \mathrm{~s}$ & Emptying of unstable traps \\
\hline 3 & IRSL $50{ }^{\circ} \mathrm{C}, 100 \mathrm{~s}$ & $\mathrm{~L}_{\mathrm{X}}$ \\
\hline 4 & $\beta$ test dose & \\
\hline 5 & Preheat $260{ }^{\circ} \mathrm{C}, 60 \mathrm{~s}$ & Emptying of unstable traps \\
\hline 6 & IRSL $50{ }^{\circ} \mathrm{C}, 100 \mathrm{~s}$ & $\mathrm{~T}_{\mathrm{X}}$ \\
\hline 7 & Return to step 1 & \\
\hline
\end{tabular}

Table 48.1 The depths from the surface of the samples in the cores examined in the present study, the radionuclide concentrations, the $\mathrm{D}_{\mathrm{e}}$ values, the measured water contents, the a-value, the natural dose rates, the IRSL ages obtained

\begin{tabular}{|c|c|c|c|c|c|c|c|c|c|}
\hline Sample & $\begin{array}{l}\text { Distance from } \\
\text { the top }(\mathrm{cm})\end{array}$ & $\mathrm{U}(\mathrm{ppm})$ & Th (ppm) & $\mathrm{K}_{2} \mathrm{O}(\%)$ & $\begin{array}{l}\text { water } \\
\text { content }(\%)\end{array}$ & a-value & $D_{e}$ Gy) & $\begin{array}{l}\text { Dose rate } \\
\text { (mGy/year) }\end{array}$ & Age (ky) \\
\hline HPD1330M1 upper & $2-4$ & $22.5 \pm 0.5$ & $2.3 \pm 0.4$ & $0.96 \pm 0.03$ & 88.29 & \multirow[t]{6}{*}{$0.04 \pm 0.004$} & $51 \pm 3$ & $4.5 \pm 0.0$ & $11.4 \pm 0.7$ \\
\hline 1330M1 middle & $11-13$ & $14.9 \pm 0.2$ & $2.7 \pm 0.2$ & $0.91 \pm 0.04$ & 95.40 & & $46 \pm 3$ & $3 \pm 0.0$ & $15 \pm 0.9$ \\
\hline 1330M1 bottom & $20-22$ & $18.1 \pm 0.2$ & $2.4 \pm 0.4$ & $0.98 \pm 0.03$ & 80.13 & & $18 \pm 1$ & $4 \pm 0.0$ & $4.5 \pm 0.3$ \\
\hline HPD1357MB upper & $2-4$ & $3.1 \pm 0.1$ & $6.4 \pm 0.5$ & $1.48 \pm 0.04$ & 94.98 & & $41 \pm 3$ & $1.5 \pm 0.0$ & $27 \pm 1.6$ \\
\hline 1357MB middle & $13-15$ & $2.7 \pm 0.1$ & $6.8 \pm 0.4$ & $1.69 \pm 0.04$ & 88.29 & & $25 \pm 3$ & $1.6 \pm 0.0$ & $15 \pm 1.7$ \\
\hline 1357MB bottom & $24-26$ & $1.6 \pm 0.1$ & $6.1 \pm 0.4$ & $1.52 \pm 0.04$ & 93.09 & & $41 \pm 2$ & $1.3 \pm 0.0$ & $32 \pm 1.3$ \\
\hline
\end{tabular}

${ }^{\mathrm{a}}$ Cosmic ray dose is not considered 


\subsection{Results and Discussion}

The typical shine down curve of one of the samples, HPD1330M1 Upper is shown in Fig. 48.1. The growth curve of the same sample is shown in Fig 48.2. These curves were very typical and all other samples showed the similar nature of curves. All the samples were analyzed using the same protocol and the result is tabulated in Table 48.1.

As seen from the Table 48.1, the ages cannot be correlated with the stratigraphic sequence, for e.g. HPD1330M1 Upper at the depth of 2-4 cm was older than HPD1330M1 Bottom at the depth of $20-22 \mathrm{~cm}$. This indicated that the ages were not sufficient to explain the history of these samples and no understanding about the hydrothermal activities could be inferred. There could

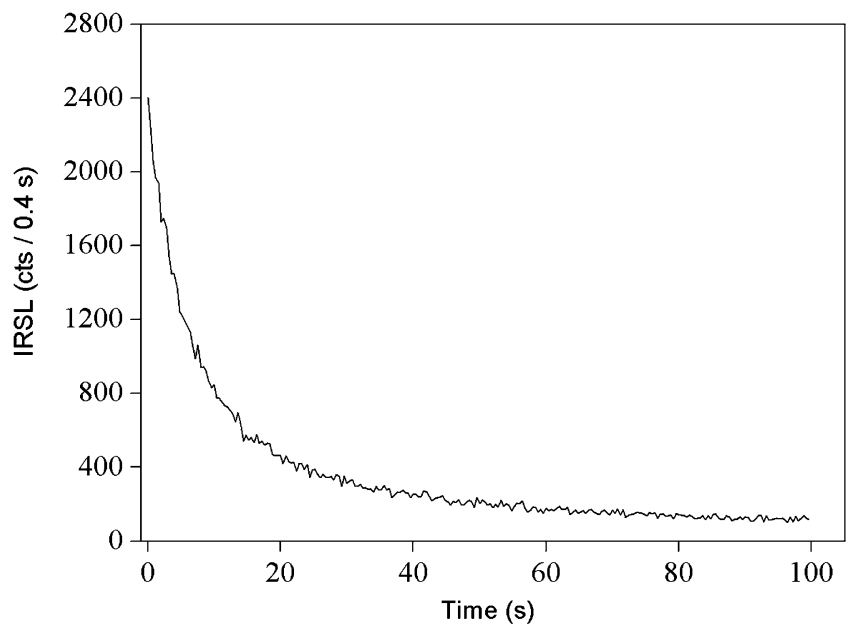

Fig. 48.1 A typical shine down curve observed in HPD1330M1 Upper

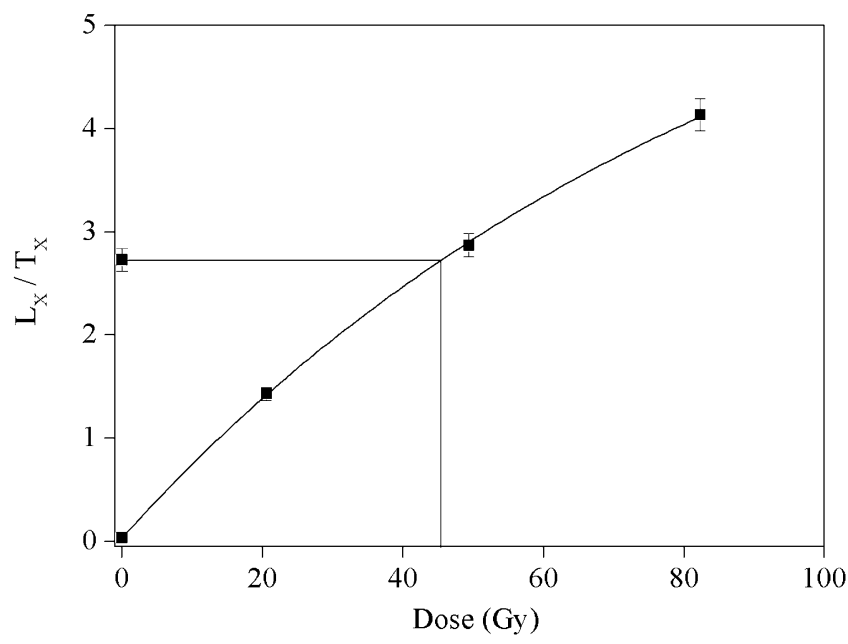

Fig. 48.2 A dose response curve obtained for HPD1330M1 Upper be two reasons for such ages- either there were uncertainties in $\mathrm{D}_{\mathrm{e}}$ measurements or in dose rate measurements.

For $\mathrm{D}_{\mathrm{e}}$, it is possible that the samples had not been reset or bleached initially due to which the ages did not show consistency. Bleaching problem could be due to insufficient light available at the sea floor to zero the predepositional luminescence signal and thus because of the partial bleaching, these ages were inconsistent with the depth of samples collected. Partial bleaching usually induces grain to grain variation of nominal $D_{e}$ values, which would be checked by single grain OSL measurements. Alternative reason for these ages could be the rework of the sediments after deposition, resulting in the mixed ages. As the sediment grains should have been mixed if this is the case, this will also induce grain to grain variation of nominal $D_{e}$ values. However, the present samples are dominated by silt and clay, and so the single grain measurement was not possible. In the single aliquot polymineral method, the signal intensity is already averaged for large number of grains and inter-grain variability in $D_{e}$ cannot be observed.

Inter-aliquot variability of $D_{e}$ values was observed in the histograms. Figure 48.3 shows for one of the samples, HPD1330M1 Upper. The histogram was closely packed and there was no indication of dispersion in $\mathrm{D}_{\mathrm{e}}$ values. Towards $\mathrm{D}_{\mathrm{e}}$ estimation using IRSL signals of feldspar, which is prone to anomalous fading (Wintle 1973), a fading correction is required. However, the fading correction was not performed since; the fading correction will systematically increase the age by not more than $10 \%$ for these young samples and the results would be un-altered.

In the case of dose rate calculations, uncertainty was imparted due to water content. The samples contained more than $80 \%$ of water with sufficient uncertainties.

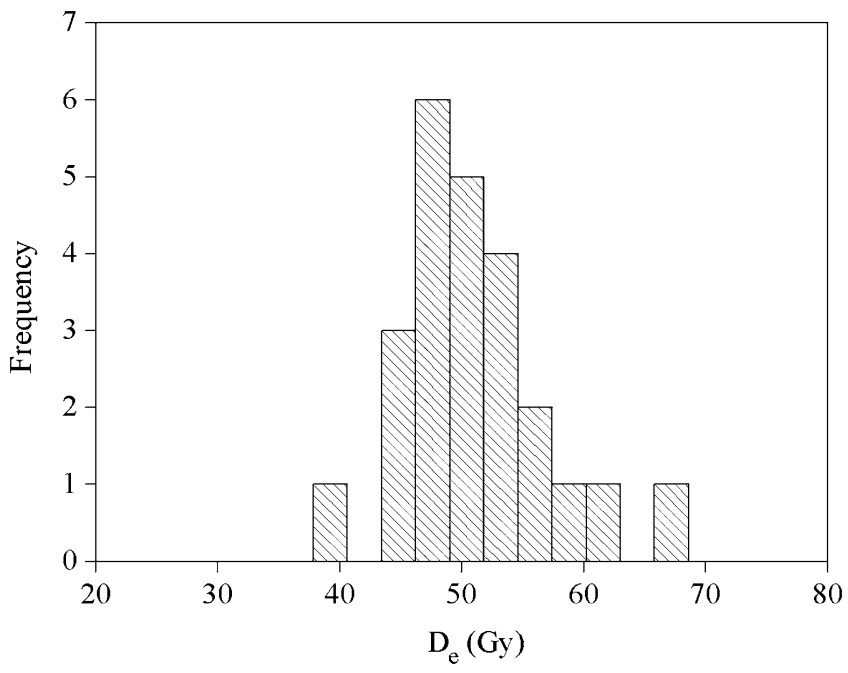

Fig. 48.3 The histogram of $D_{e}$ values of HPD1330M1 Upper, showing the distribution of $D_{e}$ values of 24 discs prepared from the sample 
Since water attenuates the doses absorbed by sediments, an uncertainty in water estimation can affect the dose rate calculations.

Another important parameter was the alpha efficiency of fine grain. Alpha efficiency was experimentally obtained in the present study for one sample HPD1357MB Bottom (randomly selected) and it was $0.03 \pm 0.002$. However, we have chosen a general value of $0.04 \pm 0.004$ for all the present samples, which were obtained by the earlier studies on fine grains by Lai et al. (2008) on Chinese loess and Biswas et al. 2013 on volcanic ashes. The above discussions indicate that applications of OSL dating method for sea floor sediments need further study for better understanding of sea floor deposition and hydrothermal activities.

\subsection{Conclusion}

Present study uses polymineral fine grain of sea floor sediments to understand the sediments' surrounding hydrothermal activities. The obtained ages are not chronological with the stratigraphic depositional sequence. Thus these ages do not indicate about the pre-depositional history or the hydrothermal activities near the sediment deposits. The two cores came out to be young, around 5-32 ka but these ages are constrained with many uncertainties. Further study is required to have better understanding for sea floor hydrothermal activities.

Acknowledgements The work was supported by Taiga project, Grantin-Aid for Scientific Research on innovative Areas (20109004) funded by the Ministry of Education, Culture, Sports, Science and Technology (MEXT), and also partly by MEXT-Supported Program for the Strategic Research Foundation at Private Universities (2011-2015, S1101036).

Open Access This chapter is distributed under the terms of the Creative Commons Attribution Noncommercial License, which permits any noncommercial use, distribution, and reproduction in any medium, provided the original author(s) and source are credited.

\section{References}

Aitken MJ (1985) Thermoluminescence dating. Academic, London Aitken MJ (1998) Introduction to optical dating. Oxford University Press, Oxford

Biswas RH, Williams MAJ, Raj R, Juyal N, Singhvi AK (2013) Methodological studies on luminescence dating of volcanic ashes. Quater Geochronol 17:14-25

Blair MW, Yukihara EG, McKeever SWS (2005) Experiences with single-aliquot OSL procedures using coarse-grain feldspars. Radiat Meas 39:361-374

Bøtter-Jensen L, Thomsen KJ, Jain M (2010) Review of optically stimulated luminescence (OSL) instrumental developments for retrospective dosimetry. Radiat Meas 45:253-257

Fujiwara T, Toyoda S, Uchida A, Ishibashi J, Nakai S, Takamasa A (2014) ESR dating of barite in sea-floor hydrothermal sulfide deposits taken from Okinawa Trough, Taiga e-book, Chap 34

Hütt G, Jaek I, Tchonka J (1988) Optical dating: K-feldspar optical response stimulation spectra. Quater Sci Rev 7:381-385

Lai ZP, Zöllerb L, Fuchsb M, Brückner H (2008) Alpha efficiency determination for OSL of quartz extracted from Chinese loess. Radiat Meas 43:767-770

Murray AS, Wintle AG (2000) Application of the single-aliquot regenerative-dose protocol to the $375 \mathrm{C}$ quartz TL signal. Radiat Meas 32:579-583

Noguchi T, Arasaki H, Oomori T, Takada J (2004) Age determination of submarine hydrothermal barite deposits by the ${ }^{210} \mathrm{~Pb} /{ }^{226} \mathrm{Ra}$ method. Bunseki Kagaku 53:1009-1013

Takamasa A, Nakai S, Sato F, Toyoda S, Banerjee D, Ishibashi J (2013) $\mathrm{U}-\mathrm{Th}$ radioactive disequilibrium and ESR dating of a baritecontaining sulfide crust from South Mariana Trough. Quater Geochronol 15:38-46

Uchida A, Toyoda S, Ishibashi J, Nakai S (2014) ${ }^{226} \mathrm{Ra}^{210} \mathrm{~Pb}$ and ${ }^{228} \mathrm{Ra}^{228} \mathrm{Th}$ dating of barite in submarine hydrothermal sulfide deposits collected at Okinawa Trough and South Mariana Trough, Taiga e-book, Chap. 41

Wintle AG (1973) Anomalous fading of thermoluminescence in mineral samples. Nature 245:143-144

Zimmerman DW (1971) Thermoluminescent dating using fine grains from pottery. Archaeometry 13:29-52 